\title{
Left Side Otalgia Caused by Acute Myocardial Infarction
}

\author{
Juyong Chung, ${ }^{1}$ Ji-Su Park², and Jin Woong Choi ${ }^{2}$ \\ ${ }^{1}$ Department of Otorhinolaryngology-Head and Neck Surgery, Wonkwang University College of Medicine, Iksan; and \\ ${ }^{2}$ Department of Otorhinolaryngology-Head and Neck Surgery, School of Medicine, Chungnam National University, Daejeon, Korea
}

\section{급성 심근경색에 의해 발생한 좌측 이통 1 예}

\author{
정주용 ${ }^{1} \cdot$ 박지수 $^{2} \cdot$ 최진웅 $^{2}$ \\ 원광대학교 의과대학 이비인후과학교실, ${ }^{1}$ 충남대학교 의과대학 이비인후-두경부외과학교실 ${ }^{2}$
}

\author{
Received September 29, 2016 \\ Revised December 5, 2016 \\ Accepted December 14, 2016 \\ Address for correspondence \\ Jin Woong Choi, MD, PhD \\ Department of Otorhinolaryngology- \\ Head and Neck Surgery, \\ School of Medicine, \\ Chungnam National University, \\ 282 Munhwa-ro, Jung-gu, \\ Daejeon 35015, Korea \\ Tel $+82-42-280-7694$ \\ Fax $+82-42-253-4059$ \\ E-mail choijw@cnu.ac.kr
}

\begin{abstract}
Otalgia consists of primary otalgia associated with disorders of the ear itself and referred otalgia due to disorders of organs that share the same innervation with the ear. Disorders of the oral cavity and laryngopharynx served by the glossopharyngeal and vagus nerves are common causes of referred otalgia. Chest pain from myocardial infarction spreads through the afferent pain pathway, especially through the sympathetic nerves in the cardiac plexus and the phrenic nerve, resulting in a typical chest pain or referred pain in the left upper extremity. However, pain spreading through the vagus nerve can theoretically cause referred otalgia. This association between the heart and ear has not been widely acknowledged, even though a referred otalgia can occasionally be the only symptom of the tragic disease, myocardial infarction, and should be taken seriously. We report a patient who complained of left otalgia as the only symptom of myocardial infarction. Korean J Otorhinolaryngol-Head Neck Surg 2017;60(6):322-5
\end{abstract}

Key Words Acute myocardial infarction - Earache - Primary otalgia - Referred otalgia . Vagus nerve.

\section{서 론}

이통(otalgia)은 이비인후과 영역에서 흔히 접할 수 있는 증 상으로 다양한 원인에 의해 발생할 수 있지만 크게는 귀의 질 환에 의하여 발생하는 원발성 이통(primary otalgia)과 귀 이 외의 부분의 이상에 의해 발생하는 연관이통(referred otalgia) 으로 구분할 수 있다. ${ }^{1)}$ 연관이통은 귀와 같은 감각신경의 지 배를 받는 다양한 기관들의 이상에 의해 발생한다고 알려져 있다. ${ }^{1)}$

심근경색은 심장에 혈액을 공급하는 관상동맥의 폐쇄로 인해 심근 조직의 괴사가 일어나는 질환으로 많은 경우 전훙 부의 흥통이나 상지의 방사통을 동반한다고 알려져 있다. ${ }^{2)}$ 심

This is an Open Access article distributed under the terms of the Creative Commons Attribution Non-Commercial License (http://creativecommons.org/licenses/by-nc/4.0) which permits unrestricted non-commercial use, distribution, and reproduction in any medium, provided the original work is properly cited.
장의 동방결절(Sinoatrial node)이나 방실결절(Atrioventricular node)은 미주신경(vagus nerve)의 지배를 받아 이곳의 허혈 이나 경색은 연관이통을 일으킬 수 있는 것으로 알려져 있 다. ${ }^{3)}$ 그러나 심근경색의 주 증상과 이통이 같이 동반된 경우에 심근경색과 연관이통과의 연관성에 대해 많이 알려져 있지 않고 대부분 심근경색의 흥통이나 방사통 또는 호흡곤란과 같은 주 증상들에 의해 이통자체가 간과되기가 쉽다.

본 저자들은 좌측 이통만이 유일한 증상이었던 심근경색 을 경험하여 문헌고찰과 함께 보고하는 바이다.

\section{증 려}

52세 남자 환자가 내원 3일 전부터 발생한 좌측의 이통을 주소로 내원하였다. 이통은 좌측 귀 안쪽에서 압박감과 함께 박통치는 양상이었다. 청력감소나 이루 등의 다른 이과적인 
증상은 없었고 시행한 신체 검사에서 양측 고막 및 외이도에 이상소견은 관찰되지 않았고 구강 및 인후두 검진에서도 이 상소견은 없었다. 전정기능검사 및 신경학적 검사에서도 이 상은 관찰되지 않았다. 과거력으로 6년 전 고혈압을 진단받았 고 1 년 전 당뇨를 진단받아 약물 복용 중이었다. 의무기록 확
인 중 1 주일 전에 흥통과 좌측 팔로 퍼지는 방사통으로 응급 실에 내원하여 당시 시행한 심전도에서 ST분절 상승이 관찰되 어 심초음파 및 혈액 심근 효소 검사를 시행하였으나 이상소 견은 없어서 퇴원한 기록이 있었다(Fig. 1A). 하지만, 내원일 에는 흥통, 방사통 및 호흡곤란 등의 심근경색의 전형적인
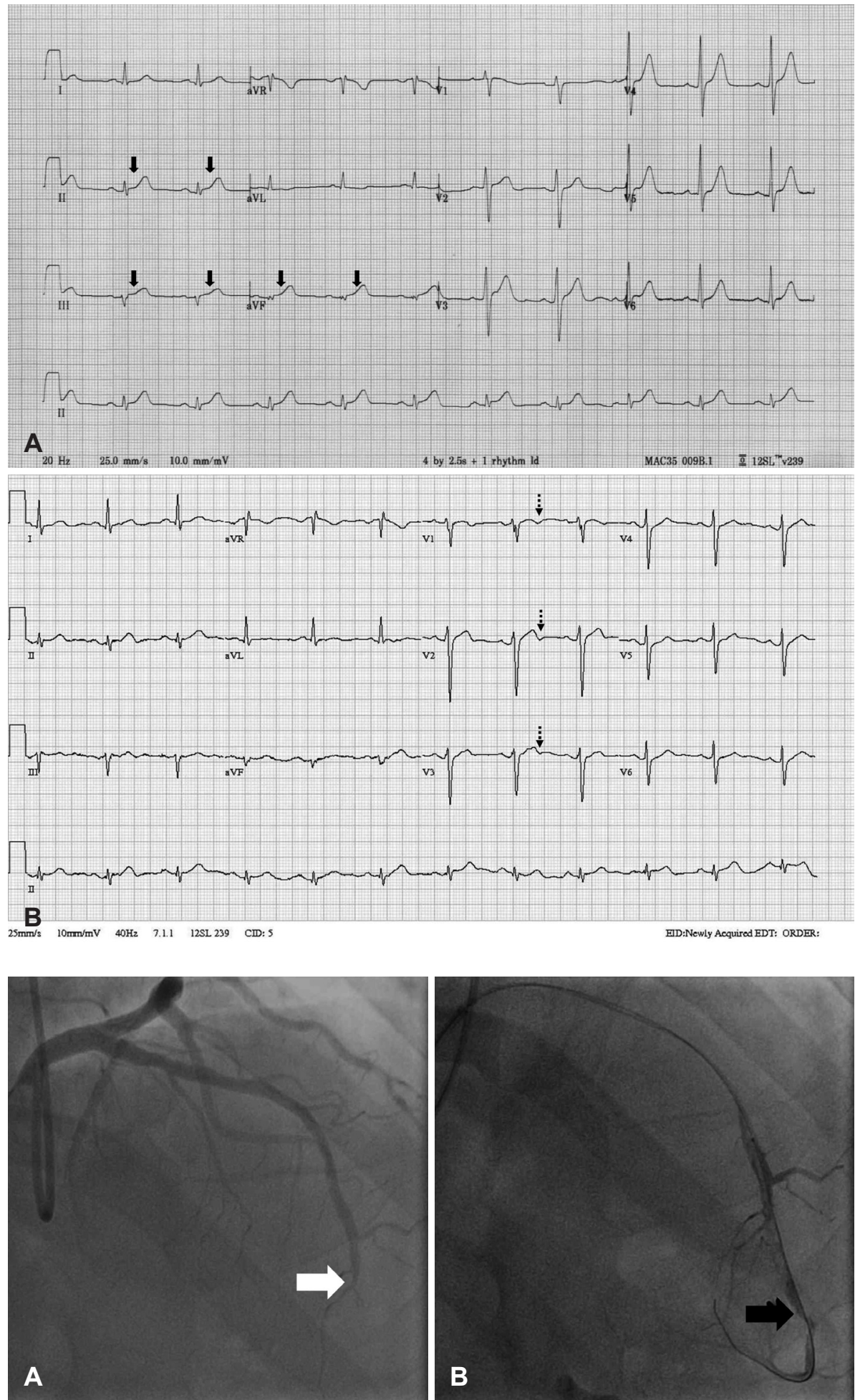
$\mathbf{B}$
Fig. 1. Electrocardiogram findings. ST elevation (arrows) was found in V2, V3 and aVF leads at first visit (A). T wave inversion (broken arrows) was newly observed in anterior leads at second visit (B).

Fig. 2. Cardiac angiography findings. Severe stenosis was observed on distal left anterior-descending coronary artery (white arrow) (A). After balloon angioplasty, stenosis of distal left anterior-descending coronary disappeared and reperfusion of blood flow was shown (black arrow) (B). 
증상들은 없었고 활력징후도 혈압 $138 / 85 \mathrm{~mm} \mathrm{Hg}$, 심박수 66 회/분, 호흡수 24 회/분, 체온 36.3 도로 정상범위로 확인되었 다. 1 주일 전의 기왕력이 있어 심전도 검사와 심근 효소 검사를 다시 시행하였다. 심전도에서 $\mathrm{T}$ 파 역전이 새롭게 관찰되었고 (Fig. 1B), 심근 효소인 troponin I이 $0.65 \mathrm{ng} / \mathrm{mL}$ (정상치: 0.01 $0.04 \mathrm{ng} / \mathrm{mL}$ )로 상승되었다. 이상의 소견으로 심근경색으로 의 심하고 이에 대한 확진 및 치료를 위해 관상동맥조영술을 실시 하였다. 관상동맥조영에서 좌전하행동맥(left anterior descending artery)의 원위부에 완전폐쇄가 관찰되었고(Fig. 2A) 풍선 혈관 성형술(balloon angioplasty)을 시행하여 막힌 혈관을 재 관류시켜 주었다(Fig. 2B). 환자가 호소했던 이통은 풍선 혈관 성형술 시술 후 소실되었다.

\section{고 찰}

귀는 다양한 뇌신경과 경추신경의 감각 지배를 받는 기관으 로 귀 자체의 질환뿐만 아니라 다양한 원인에 의해서 통증이 발생할 수 있다. 급성 외이도염, 악성외이도염, 급성중이염 및 외이도 악성종양과 같은 귀질환 등에 의해서 발생하는 이통을 원발성 이통이라고 하며 귀와 같은 신경의 지배를 받는 다른 기관의 질환에 의해 발생하는 이통을 연관이통이라 한다.1)

귀에는 4가지의 뇌신경(삼차신경, 안면신경, 설인신경, 미주 신경)과 제 2,3 경추신경이 분포하는데 이러한 감각신경들은 귀뿐만 아니라 인체의 다양한 기관의 감각을 담당한다. 하지 만, 인간의 두뇌는 같은 경로로 올라오는 내장감각과 체성감 각 지배영역의 신호를 구분할 수 없기 때문에 이러한 연관이 통이 발생한다고 알려져 있다.) 예를 들어, 측두하악관절 및 구강은 $\mathrm{V}$ 뇌신경의 지배를 받는데 Costen's 증후군같이 측 두하악관절의 이상으로 교합에 문제가 있거나 치주농양 (periodontal abscess)이 있는 경우 연관이통을 호소할 수 있 다. 또한 편도염이나 후두질환 등도 각각 설인신경, 미주신경 을 통해 연관이통을 유발할 수 있다.5) 이러한 연관이통은 남 성보다는 여성에서, 소아보다는 성인에서 흔히 발생하는 것으 로 알려져 있다.

심장은 심장신경얼기(cardiac plexus)로부터 신경지배를 받 는데, 이 심장신경얼기는 반사 자극이나 통증 자극을 전달하 는 내장들신경뿐만 아니라 교감신경과 부교감신경이 형성하 는데 이 내장들신경은 하부 경추 및 흥추 신경절의 지배를 받 는다. 따라서 심근경색으로 인해 심근에 손상이 발생하면 전 형적인 전흥부의 통증이나 상지의 방사통이 발생한다. 하지 만, 관상동맥을 따라 분포하는 미주신경 또한 동방결절과 방 실결절을 포함하여 심장의 부교감자극을 담당하는데, 이를 통하여 심장박동수와 수축에 영향을 미치는 것으로 알려져
있다. 따라서 이 부위들의 손상들은 연관이통을 일으킬 수 있다. ${ }^{6-10)}$ Amirhaeri와 Spencer ${ }^{7}$ 는 우측 관상동맥 폐쇄에 의 한 심근경색 때문에 발생한 연관이통을 보고한 바 있다. 이것 은 우측 관상동맥의 분지에서 혈액공급을 받는 동방결절이 우 측 미주신경의 지배를 받기 때문에 발생한 것으로 생각된다.

그러나 문헌고찰을 통해 확인해 본 결과 아직까지 본 증례 처럼 좌측 이통만 발생한 경우는 확인할 수 없었다. 본 증례 의 경우 좌전하행동맥의 원위부에 경색이 발생하였는데, 일 부의 경우 이 혈관의 분지가 방실결절에 분포하고 방실결절은 좌측 미주신경의 지배를 주로 받기 때문에, 같은 신경의 지배 를 받는 좌측 귀의 이통이 발생한 것으로 생각된다. 실제로, 동방결절은 $60 \%$ 정도에서, 방실결절은 $80 \%$ 정도에서 우측 관상동맥의 분지에서 혈액공급을 담당하고, 그 이외의 경우 에는 좌측 관상동맥이 담당한다고 알려져 있다. 동방결절과 방실결절의 부교감신경의 분포는 양측의 미주신경이 모두 관 여하지만 우측 미주신경은 주로 동방결절에 좌측 미주신경 은 방실결절에 분포한다. ${ }^{11-13)}$ 따라서, 심근경색에서 발생할 수 있는 연관이통은 기존에서는 주로 우측에서 발생한다고 보고되어 있으나, 경색이 일어나는 부위에 따라 양측이나 좌 측의 이통도 증상으로 나타날 수 있을 것으로 생각된다.

흥통을 동반하지 않는 심근경색은 그 빈도가 흥통을 동반 한 심근경색보다 드물고 늦은 진단으로 인해 치료의 지연이 발생할 수 있어서 예후도 좋지 않은 것으로 알려져 있다. ${ }^{14)}$ 특 히, 연관이통이 유일한 증상으로 나타나는 경우는 매우 드물 며 이통이 유일한 증상일 경우 그 진단 자체가 매우 어려울 수 있다. ${ }^{15)}$ 심근경색에 의한 이통은 대부분 10 일 이내에 급성으 로 나타나는 경우가 대부분이므로 고령, 당뇨 또는 고혈압 등 의 심근경색의 위험인자들을 가진 환자에서 귀 자체의 병변 이 없는 급성 이통의 경우에는, 심근경색의 가능성에 대해서 반드시 염두에 두어야 하며 필요한 경우 심전도 검사 및 혈 액검사등이 필요할 것으로 사료된다.

\section{REFERENCES}

1) Yoo MH, Park HJ. Diagnoisis and treatment of otalgia. Korean J Otorhinolaryngol-Head Neck Surg 2013;56:191-200.

2) Canto JG, Shlipak MG, Rogers WJ, Malmgren JA, Frederick PD, Lambrew CT, et al. Prevalence, clinical characteristics, and mortality among patients with myocardial infarction presenting without chest pain. JAMA 2000;283(24):3223-9.

3) Ely JW, Hansen MR, Clark EC. Diagnosis of ear pain. Am Fam Physician 2008;77(5):621-8.

4) Scarbrough TJ, Day TA, Williams TE, Hardin JH, Aguero EG, Thomas CR Jr. Referred otalgia in head and neck cancer: a unifying schema. Am J Clin Oncol 2003;26(5):e157-62.

5) Charlett SD, Coatesworth AP. Referred otalgia: a structured approach to diagnosis and treatment. Int J Clin Pract 2007;61(6):1015-21.

6) Rothwell PM. Angina and myocardial infarction presenting with pain confined to the ear. Postgrad Med J 1993;69(810):300-1. 
7) Amirhaeri S, Spencer D. Myocardial infarction with unusual presentation of otalgia: a case report. Int J Emerg Med 2010;3(4): 459-60.

8) Sheikh M, Adlakha S, Chahal M, Bruhl S, Pandya U, Saeed B. "Cardiac otalgia": acute coronary syndrome masquerading as bilateral ear pain. Cardiol J 2010;17(6):623-4.

9) Ocak U, Avşaroğullari L, Kaya MG, Özmen Y, Taşlıdere B, Güldeste EA, et al. Acute coronary syndrome presenting with earache and sore throat. Am J Emerg Med 2014;32(5):487.e5-6.

10) Dundar R, Kulduk E, Kemal Soy F, Sengul E, Ertas F. Myocardial infarction as a rare cause of otalgia. Case Rep Otolaryngol 2014;2014: 106938.

11) Moore KL, Dalley AF, Agur AMR. Clinically oriented anatomy. 6th ed. Philadelphia: Lippincott Williams \& Wilkins;2010.
12) Martin P. The influence of the parasympathetic nervous system on atrioventricular conduction. Circ Res 1977;41(5):593-9.

13) Mauro MPS, Patronelli F, Spinelli E, Cordero A, Covello D, Gorostiaca JA. Nerves of the heart: a comprehensive review with a clinical point of view. Neuroanatomy 2009;8(1):26-31.

14) Kreiner M, Okeson JP, Michelis V, Lujambio M, Isberg A. Craniofacial pain as the sole symptom of cardiac ischemia: a prospective multicenter study. J Am Dent Assoc 2007;138(1):74-9.

15) Herlitz J, Karlson BW, Richter A, Strömbom U, Hjalmarson A. Prognosis for patients with initially suspected acute myocardial infarction in relation to presence of chest pain. Clin Cardiol 1992; 15(8):570-6. 